\title{
DIGITAL PHOTOGRAMMETRY FOR THE GEOMETRICAL ANALYSIS OF THE UMBRELLA-SHAPED DOME IN BAIA (NAPLES)
}

\author{
Licinia Aliberti $^{1 *}$, Miguel Ángel Alonso-Rodríguez ${ }^{2}$ \\ ${ }^{1}$ ESNE, University School of Design, Innovation and Technology. Camilo José Cela University, Madrid, Spain- \\ licinia.aliberti@esne.es \\ ${ }^{2}$ ETSAM. Universidad Politécnica de Madrid, Spain - miguel.alonso@upm.es
}

\section{Commission VI, WG VI/4}

KEY WORDS: Heritage, geometrical analysis, Baia, dome, photogrammetry

\begin{abstract}
:
This paper is focused on the use of photogrammetric measurement techniques for the valorization of architectural and archaeological heritage. The functionality of this system allows operating with unfavourable conditions and pursues the accuracy of the measurement. This case of study presents a complex situation. Currently half part of the octagonal room annexed to the Temple of Mercury in Baia is underwater. Moreover the level of water may grow due to the characteristic movement of the soil in this area. The accuracy of photogrammetric method and the high definition of the camera used for the photo captures allow the reconstruction of the interior of the dome. The particular geometry of this surface stresses the relevance of a complete documentation of the dome. The research describes the method and tools used to realize this survey in difficult conditions and then analyze the geometry of the interior of the dome. In order to develop the geometrical analysis we carried on a series of operations on the point cloud and the survey model. The study of the photogrammetric model and the construction of an ideal model based on geometrical laws generate useful material to understand this complex vault.
\end{abstract}

\section{INTRODUCTION}

\subsection{Research main goals}

This paper is focused on the use of photogrammetric measurement techniques for the valorization of architectural and archaeological heritage. The continuous evolution of the building over time needs a monitoring action to document its conditions. These achived data may offer important information to understand ancient buildings.

In this sense digital photogrammetry is a powerful tool. The functionality of this system allows operating with unfavorable conditions and pursues the accuracy of the measurement. The case study presents a complex situation. Currently half part of the octogonal room annexed to the Temple of Mercury in Baia is underwater. The level of water may grow due to the movement of the soil characteristic in this area, so that a survey of its current state of conservation is necessary.

One of the main goals of this research is to apply the digital photogrammetry to an archaeological building in difficult conditions and to test the efficacy of the method.

The accuracy of photogrammetric method and the high definition of the camera used for the photo captures allow the reconstruction of the interior of the dome. The particular geometry of this surface highlights the relevance of a complete documentation of the dome.

The research describes the method and tools used to realize this survey in difficult conditions and then analyzes the geometry of the interior of the dome. In order to develop the geometrical analysis we carried on a series of operations on the point cloud. The study of the photogrammetric model and the construction of an ideal model based on geometrical laws generate useful material to understand this complex vault.

The special state of conservation of the octagonal room annexed to the Temple of Mercury offers a good study case. The vault is conserved in all its parts and it seems not to have been modified by architectural restoration.

There are many studies about the underwater archaeological site of Baia but there aren't recent publications about the thermal complex on land. We can find some information in the work of Borriello and D'Ambrosio (1979) where the authors presented a general survey of the whole archaeological site. Considering the date of execution, a new survey based on current methods and tools may be very useful. Furthermore studying this single vault it is possible to deepen in details and to use a different scale of definition in the graphical documentation.

As a principal goal this research aims to maximise the data management of the survey in order to develop a geometrical analysis of the inner surface of the dome. Since the octagonal room is an example of umbrella-shaped domes this work may offer new contributions to the knowledge of early Roman vaults.

\subsection{Description of the case study}

The case study is the octogonal room annexed to the so called Temple of Mercury in the archaeological site of Baia near Naples. This ancient building dates in the 2 nd century AD and still presents an umbrella-shaped dome completely conserved. The complex geometry of this vault is the result of a large experimentation realized by the Roman constructors during time (Lancaster 2005; Lucchini 1997; Rakob 1988; Aliberti 2013). Roman concrete expresses its capabilities with special

* Corresponding author 
evidence in the design and construction of the internal surfaces of the vaults. Here this material offered the possibility of a new experimentation on different geometries.

The geometry of Roman vaults had a relevant evolution since the first examples of conical shape domes on circular plants of the thermal complex in Pompei until the complex vault of the Hadrianic Villa with alternated convex and concave surfaces. A great number of Roman domes have a spherical shape that was experimented in different scales. The most impressive example is unquestionably the enormous dome of the Pantheon in Rome.

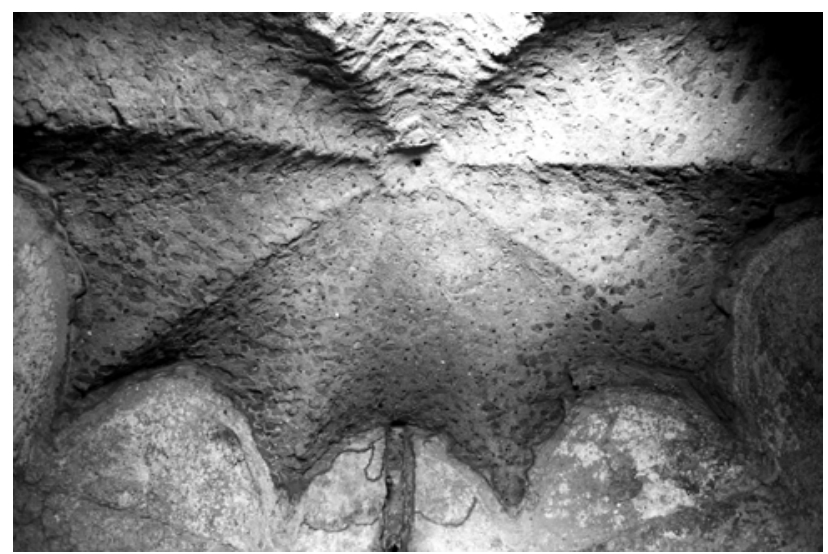

Figure 1. Photograph of the vault.

The octagonal room annexed to the Temple of Mercury presents one of the best conserved examples of a vault with complex surface. The constructive system used in Roman domes is based on the overlapping of horizontal layers. Considering the small dimensions of the vault the main difficulty during the building was the design and construction of the formwork.

Observing the reduced thickness of the holding walls and the monolithic structure of the dome some scholar consider it as the first example of umbrella-shaped vault in Roman architecture (Sanpaolesi 1971, 14).

Although the room is completely conserved it is not entirely accessible due to the flooding of the floor. This condition is caused by the bradyseism, a progressive process typical of volcanic areas that generates the gradual descent of part of the Earth's surface caused by emptying of underground magma chambers and hydrothermal activity. The complex amount of ground vertical movements is a result of the vitality of the volcanic area of the Campi Flegrei located in the Neapolitan region (Passaro 2012).

The level of the access of the octogonal room is currently under the water table as in the Temple of Mercury, where the first image describing the beginning of this process dates in the Eighteenth century (Paoli 1768). The progressive flooding of the floor during time reaches nowadays almost half height of the Temple of Mercury.

The plan view of the upper part of the room describes an octagon and the inscribed circumference has an average diameter of $5,92 \mathrm{~m}$ (personal observation). The inner surface has an umbrella shape with eight convergent wedges. The structure realized with Roman concrete is partially irregular and it has a rough surface. The material used is tufa stone with great quantity of Roman mortar.

The building has a quadrangular window on the top of the entry. This opening gives natural illumination to the room together with the entrance. The window is located in one side of the octagon and ends just before the beginning of the wedges of the dome (Borriello 1979; personal observation). The West side of the room is partially underground as the site presents a considerable difference of ground levels.

\section{RESEARCH}

\subsection{Photogrammetric survey}

The study of the dome develops from a digital photogrammetric survey based on automated processes. The research is articulated into different steps of data collection, processing and management of results.

A specific software for the photogrammetric reconstruction was used to obtain the three-dimensional models and other CAD software for vectorial drawing of graphic restitution. In this case we used the software Agisoft Photoscan Pro for photogrammetric reconstruction. It allows a sequence of operations and high developed automatic proceedings and helps to control the specific settings that guide the reconstruction through the kind of results intended by the research.

The capture of high quality photos is an important factor in this research. We used a full frame digital reflex camera and fixed lens. The camera used is a Canon EOS 5D with a CMOS sensor $35,8 \times 23,9 \mathrm{~mm}$ with $13,3 \mathrm{MP}$ (12,8 MP effective). The fixed lens used are Canon $50 \mathrm{~mm}$ (1:1.4) and Canon $24 \mathrm{~mm}$ (1:2.8). To obtain the restitution we finally used only the picture taken with the $24 \mathrm{~mm}$ lens, which assured a large overlap between the images.

The photos were taken with daily light without flash to respect the protection of the archaeological object. This fact explains the use of such elevated ISO sensitivity and large exposure time.

The conditions of data collection were constrained because of the flooding of the floor. The photos were taken from only one position situated almost in the entry of the room. The accessible floor is at a higher height with respect to the original level so that it is relatively close to the inner surface of the vault. However the floor that can be used is reduced and doesn't permit to locate the camera in opposite points of view. We have to highlight that the circular sweeping of the photos from only one point of view isn't the best way to realize the data acquisition. However the different inclinations of the camera during the capture of the images and the small dimensions of the building allowed the correct orientation of images in the photogrammetric process.

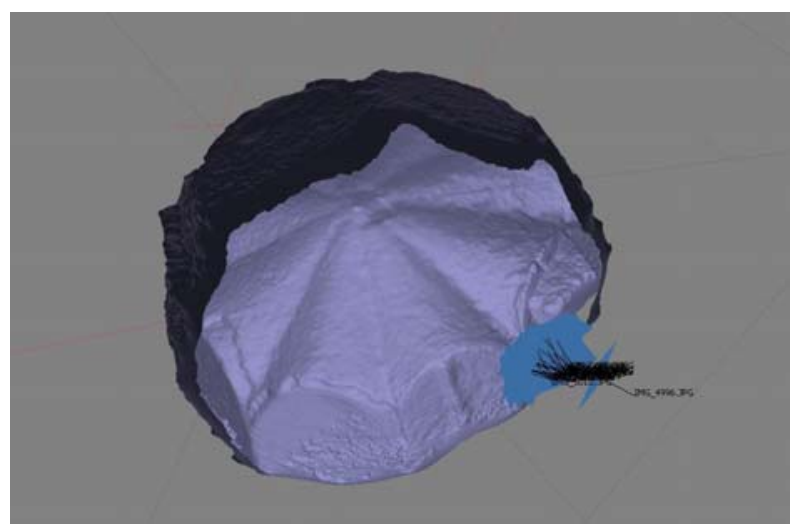

Figure 2. Oriented photographs used for the digital photogrammetric survey of the vault.

We obtained the calibration of the camera with the automated method used by the software. The lens and camera used were easily recognized for the correct calibration. Camera calibration 
was realized automatically during the alignment and identification process of images. The proceedings applied by Agisoft Photoscan Pro have been tested and ensure an excellent calibration of the camera (Ippoliti, Meschini \& Sicuranza 2015). This automatic calibration is here applied after verifying the correct coherence between one first photogrammetric model and some reference measurements registered with a laser distance meter.

The images were aligned and a three-dimensional model was obtained through the software. We applied automated proceedings SFM (Structure From Motion) to the tie points model and we obtained a high definition point cloud that includes its chromatic information. Considering the limited dimensions of the vault we could process photos in high level and generate a detailed dense point cloud.

During the data collection we registered some direct measures using a laser distance meter. Due to the irregularity of the rough surface and the impossibility to reach all the sides of the room we couldn't realize a complete direct survey. As principal data we registered the distance between the entrance edge and the opposite. We used this value as the reference to scale and orient the survey model.

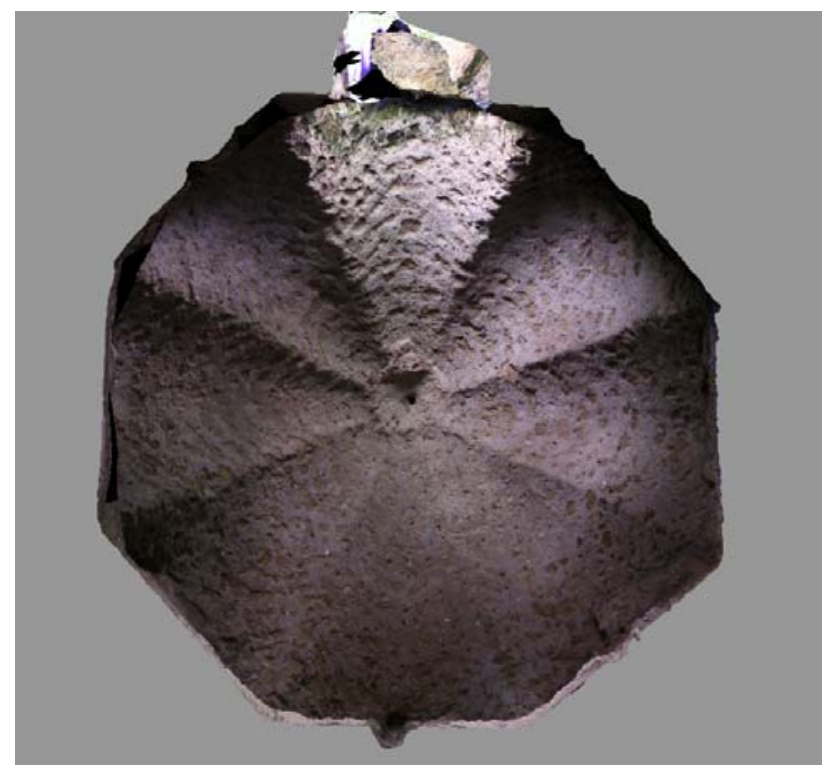

Figure 3. Orthogonal view of the survey model of the dome and texturing.

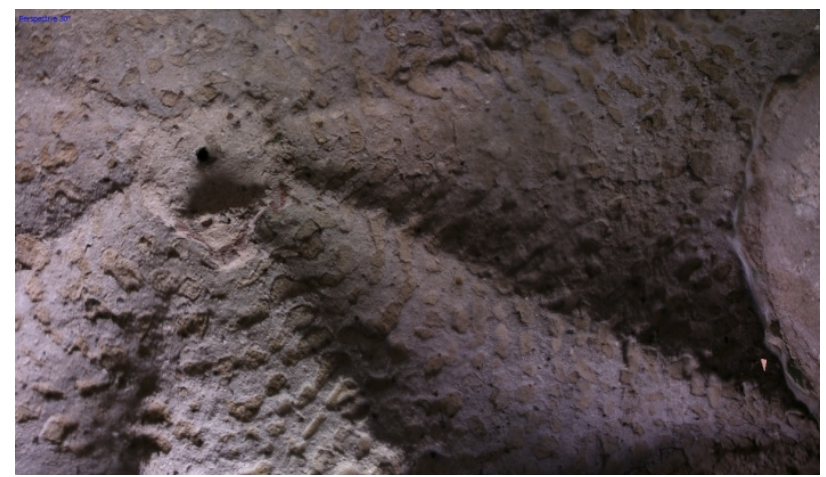

In order to elaborate the geometrical analysis we generated a mesh surface from the point cloud. This continuous surface can be used in vector drawing software and offers detailed information for the architectural study.

The mesh surface is also the support to obtain the textured model. The process generated a high definition of the textured surface due to the quality of photographic images used. This result is relevant in the study and documentation of the building because it offers direct information about the state of conservation of the surface of the structure. From a constructive point of view it could be useful to study the distribution and characteristics of materials of the vault.

\subsection{Geometrical analysis}

The geometrical analysis aims to understand the design of the inner surface of the dome and to reconstruct the ideal model. The surface of the intrados is subdivided into concave segments that converge towards the vertex. They make a composition of wedges shaped surfaces. Studying the survey model we can calculate the curvature of the wedges that depend from the concavity of the surface and the height of the top vertex of the dome.

The correct transition between the point clouds and the continuous model is still a challenge in current architectural survey. Elements like lines and surfaces are key tools in architectural studies (Canciani 2013). On the other hand we have to recognise that the current tools of the point cloud management have evolved considerably and can offer direct data of the survey model. This work aims to study the management of point cloud and of the mesh surface and to extract useful information for geometrical analysis.

In order to realize that geometrical analysis we applied some average calculations that are useful to determine the ideal model of the vault. These calculations were developed using measures of the survey model. Some of the data were extracted directly from the point cloud and other from the mesh surface using a vector drawing software.

Some of the average calculations were taken using the numerical data collected and some of them were extracted directly from the survey model using the software Rhinoceros. In addition to the easy tools of management for point clouds and mesh models this software can apply different average calculations to extract geometrical shapes.

The first step was to find the average values of the principle elements and so describe the general design of the dome. The creation of the ideal model was studied at the same time. This process required some additional data and a continuous feedback between the two proceedings.

The correct approximation of the measure of the edges was difficult to obtain due to the irregularity of the surface and to the rounded sides of the room. Finally its average value is 2.45 $\mathrm{m}$. The same constraints influenced the measuring of the radio of the candle. It presents great irregularities at its beginning at the wall where its average radius is $1.15 \mathrm{~m}$. The wedges reduce their dimension and converge in a circle at the top of the dome with an average diameter that may be approximated to $60 \mathrm{~cm}$. The circle is irregular and the separation between the wedges and the circle isn't a clear line so that this is only a guidance value. At the top of the dome there is a small circular hole of approximated $5 \mathrm{~cm}$ diameter.

The single values and the average values of the principal elements of the vault are annexed below in the Table 2 .

Figure 4. Detail view of the textured surface. 


\begin{tabular}{|l|c|c|}
\hline & Single values [m] & $\begin{array}{c}\text { Average } \\
\text { values [m] }\end{array}$ \\
\hline $\begin{array}{l}\text { Distance } \\
\text { between edges }\end{array}$ & $5.92-5.85-5.84$ & 5.92 \\
\hline Edge & $\begin{array}{c}2.45-2.29-2.51-2.45 \\
2.49-2.43-2.61-2.38\end{array}$ & 2.45 \\
\hline $\begin{array}{l}\text { Radio max of } \\
\text { candle }\end{array}$ & $\begin{array}{c}1.22-1.23-1.17-1.13-1.15 \\
-1.12-1.11-1.08\end{array}$ & 1.15 \\
\hline
\end{tabular}

Table 2. Average calculations of the principal elements of the vault

These values are relevant for the interpretation of the ideal geometry of the vault. However we realized some more analysis of the form of the surface. It presents smooth transitions from opposite curvatures and it reduces its dimensions as it rises. The transition between different surfaces is a complex issue to analyse.

We obtained a series of horizontal sections at $10 \mathrm{~cm}$ distance and 8 radial sections of the point cloud. Along the axes of the wedges we extracted 4 radial sections and other 4 sections were taken in the separation lines between the wedges. The sectors of the dome aren't exactly aligned but we consider useful to have complete lines of sections and not to divide each of them in two parts. In the extraction of these intersection lines we applied a high approximation to the point cloud to document with detail the irregularity of the surface. This set of data describes the shape of the vault and can be used in architectural analysis.

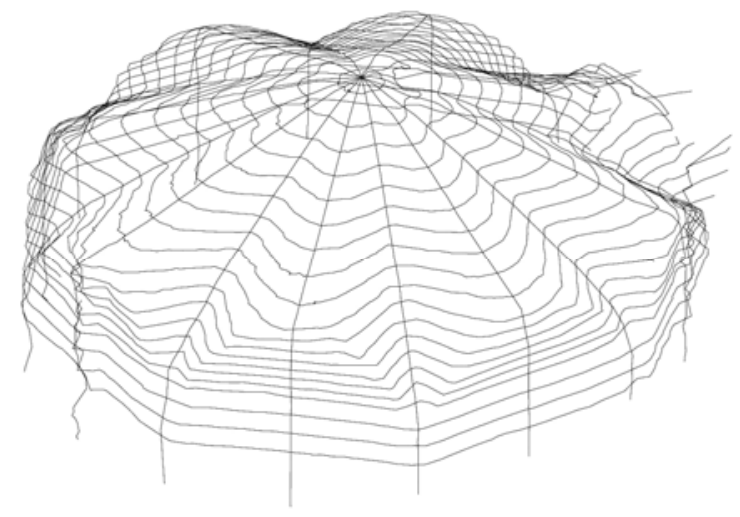

Figure 5. Horizontal and radial sections of the points cloud.

The horizontal and vertical sections show the form of the vault and the irregularity of the surface.

The plan of the room obtained cutting the building about $50 \mathrm{~cm}$ from the beginning of the vault is an irregular octagon. The inferior part of the room is completely submerged and we couldn't study the lower level of the room. But since the object of the investigation is the inner surface of the vault we consider the upper level as useful to determine the shape of the room.

There are evident differences between the edges and their reciprocal inclinations. The angles between the axes present different values from the ideal $45^{\circ}$ that should reflect a uniform division of the $360^{\circ}$ angle in 8 equal parts.

The setting-out of the octagonal room may have been difficult due to the particular situation of the building that is partially underground. Moreover the pressure of the ground may have caused some deformation of the structure during the centuries. Indeed Roman builders used to show a precise setting-out in this kind of geometrical shapes. They achived very high precision in the setting-out of more complex design as the distribution of the coffers of the Pantheon dome in Rome (Aliberti 2017) or the main axes of the Coliseum (Pelletti 1989). The thickness of the vault can be measured in the window hole where we can observe the structure. The rough surface and the irregularity of the hole make difficult the measuring of the thickness. From the study of the survey model we can state that the thickness of the vault at the height of the higher part of the window is $65 \mathrm{~cm}$. We can't determine if the dome has different thickness because the external surface is partially underground.

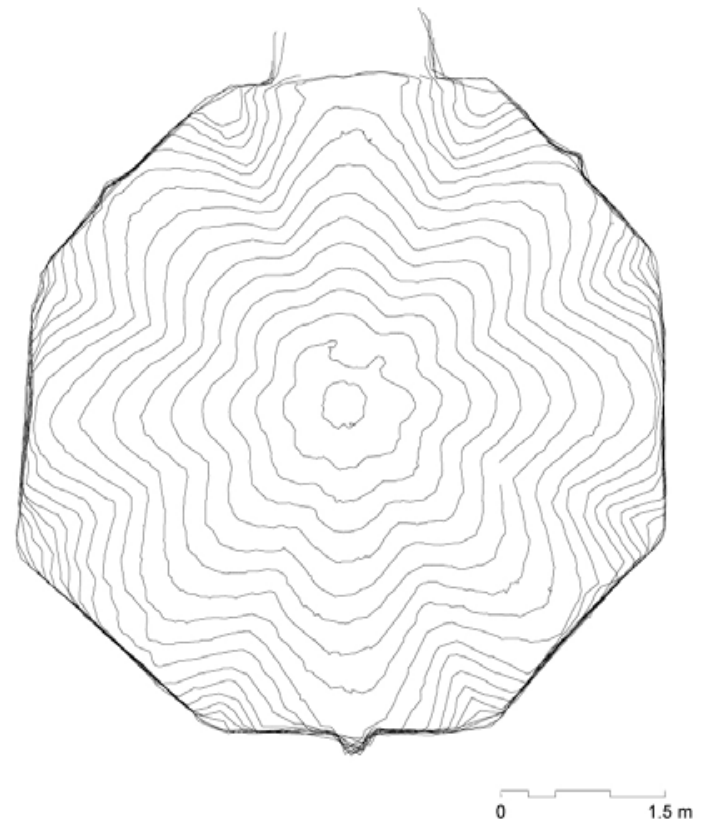

Figure 6. Plan view of the horizontal sections of the points cloud (10 cm distance).

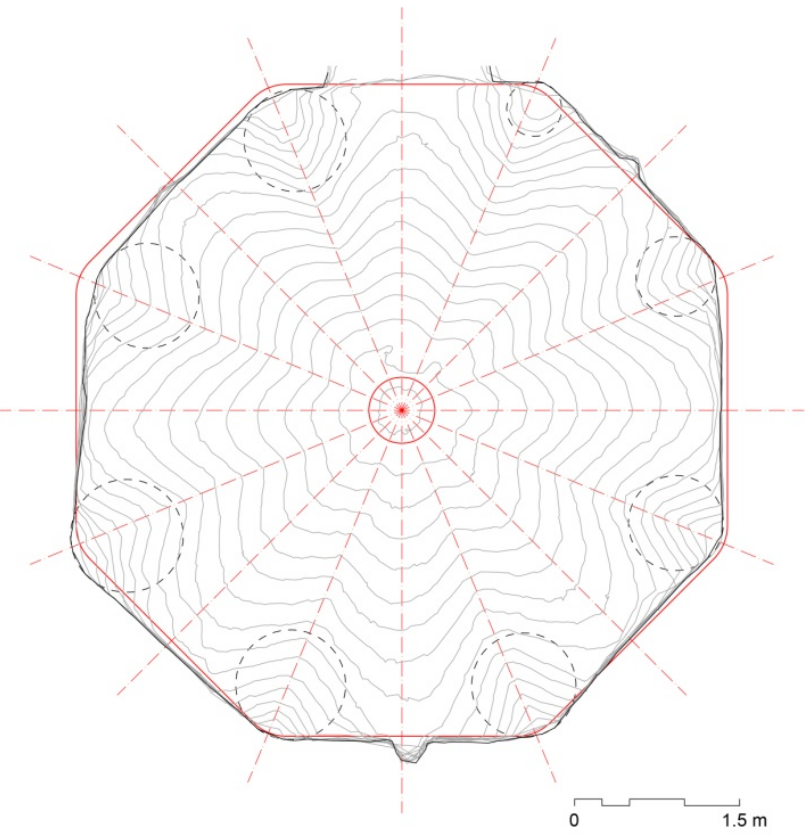

Figure 7. Plan view of the horizontal sections of the points cloud (10 cm distance). 
The construction of the ideal model is based on the average values obtained from the survey model. We first create an octagon with $2.45 \mathrm{~m}$ edge and we verify that the distance between opposite edges is 5.91 that is very similar to the $5.92 \mathrm{~m}$ of the survey model. The general setting-out seems to respect the correct construction of the octagon but the plan of the room is clearly deformed if compared with the ideal shape.

The sides are rounded and the connection arc measures an average value of $43 \mathrm{~cm}$. The calculation of the single values was obtained by creating approximated circumferences in each rounded side with graphical tools that apply average estimations.

The height of the dome is difficult to determine due to the irregularity of the wedges. The average values registered was $1.15 \mathrm{~m}$ height calculated between the upper point of the beginning arc of the wedges and the circle at the top of the dome.

According to the analysis of the survey model the radius of the beginning arc of the wedges is $1.15 \mathrm{~m}$. This fact indicates that it doesn't occupy the entire edge. The inner surface of the vault is a continuous surface so that there is a connection surface between the wedges. The arcs of continuous edges are connected by a curve and the whole surface is composed by conical hollow teeth connected by small convex surfaces. The alternation between different surfaces and the experimentation of new geometries is characteristic of Hadrianic architecture. In the Hadrian Villa we find some examples of complex vaults that cover spaces with the alternation of arcs and lines in plan (Lucchini 1997). In this specific case study the concave surface is significantly wider than the convex part and the dome is usually defined as an umbrella-shaped vault.

The concave parts are truncated conical surfaces. The starting arc is half of a vertical circumference matching with the sides of the octagon. The ending arc is a part of the horizontal circumference on top of the vault as the wedges are cut with a horizontal plan.

The lateral lines that define the surfaces converge into a point situated $15 \mathrm{~cm}$ higher than the top of the vault. Roman builders decided not to reach the vertex and cut the surfaces at a lower height probably in order to simplify the construction of the top of the vault. The ending of Roman vaults was a problematic issue from a constructive point of view. The introduction of the oculus in spherical domes was indeed useful to avoid the problem to cover the upper part of the structure.

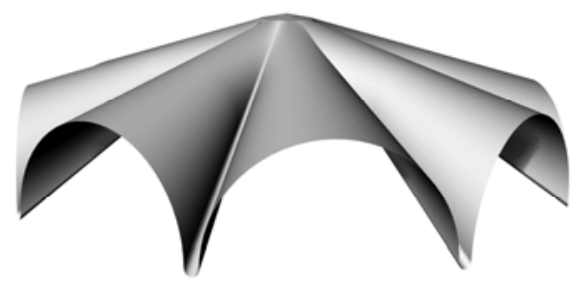

Figure 8. View of the ideal model.

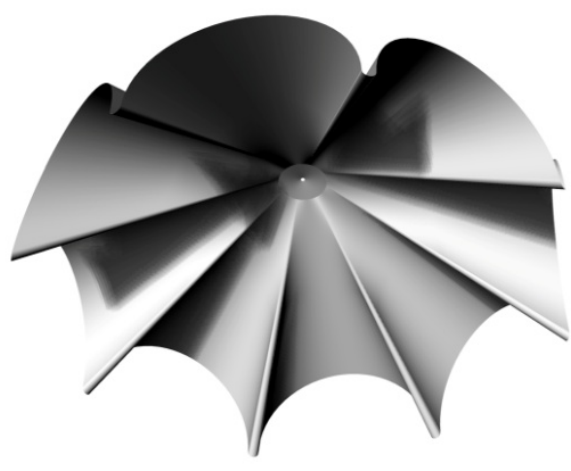

Figure 9. View of the ideal model.

\section{CONCLUSIONS}

This work confirms the role of digital photogrammetry as a powerful method for heritage survey. The study of archaeological and architectural rests deserves objective data. Moreover the documentation of the state of conservation of the buildings is important to improve their conservation and to register their transformation during time. The graphical restitution is particularly significant in this ancient building that may suffer great damage due to its special situation.

The results obtained with the difficult conditions of the data collection in the octagonal room are an example of the great versatility of the digital photogrammetry with structure for motion method. Furthermore the export proceeds used reflect the advances realized in this field in the last years. The necessity of the generation of continuous surfaces and lines in architectural analysis contributes to the development of complex method of data extraction from the point cloud.

Finally the most evident result of this research is the geometrical analysis of the vault. This contribution offers new information of a building that doesn't appear in the recent scientific publications. The vault of the octagonal room is a very relevant example of complex experimentation of Roman builders. This work may contribute to document its state of conservation, to study its geometry and to reassert its importance in architectural heritage.

\section{REFERENCES}

Aliberti, Licinia. 2013. Cúpulas clásicas romanas: geometría y construcción. In: Actas del VIII Congreso Nacional de Historia de la Construcción, V1, Madrid, pp. 13-23.

Aliberti, L. \& M.A Alonso-Rodríguez. 2017. "Geometrical Analysis of the Coffers of the Panteon's dome in Rome". In: Nexus Network Journal. Architecture and Mathematics, Vol. 19, N. 2, pp. 363-382.

Borriello, M. \& A. D'Ambrosio. 1979. Baiae-Misenum. Firenze: Leo S. Olschki.

Canciani, M., Falcolini, C., Saccone, M., \& Spadafora, G. 2013. From point clouds to architectural models: algorithms for shape reconstruction. In: The International Archives of the Photogrammetry, Remote Sensing and Spatial Information Sciences, Trento, Italy, Vol. XL-5/W1, pp. 27-34. 
Gambardella, Alfonso. 2002. Dal Pantheon a Brunelleschi. Architettura, costruzione, tecnica. Napoli: Edizioni Scientifiche Italiane.

Ippoliti, E., Meschini, A. \& Sicuranza, F. 2015. "Structure From Motion systems for architectural heritage. A survey of the internal loggia courtyard fo Palazzo dei Capitani, Ascoli Piceno, Italy". In: 3D-ARCH 2015 "3D Virtual Reconstruction and Visualization of Complex Architecture”, ISPRS, Avila, Spain, pp. 53-60.

Lancaster, Lynne C. 2005. Concrete Vaulted Construction in Imperial Rome. Innovations in Context. Cambridge: Cambridge University Press.

Lucchini, Flaminio. 1997. "Le cupole di Adriano". En Lo specchio del cielo. forme, significati, tecniche e funzioni della cupola dal Pantheon al Novecento, ed. Claudia Conforti, Milano: Electa, pp 9-21.

Murphy, M., McGovern, E. \& Pavia, S. 2013. "Historic Building Information Modelling: Adding intelligence to laser and image based surveys of European classical architecture". In: ISPRS Journal of Photogrammetry and Remote Sensing, 76, pp. $89-102$.

Paoli, Paolo Antonio. 1768. Avanzi delle antichità esistenti a Pozzuoli Cuma e Baia. Antiquitatum Puteolis Cumis Baiis existentium reliquiae. Firenze-Napoli.

Pelletti, Marco. 1989. "Note al rilievo del Pantheon". In: Quaderni dell'Istituto di Storia dell'Architettura XIII , pp 10-8.

Rakob, Friedrich. 1988. Römische Kuppelbauten in Baiae. Mitteilungen. Des Deutschen Archaologischen Instituts, Romische Abteilung, pp. 257-301.

Rasch, Jürgen J. 1985. Die küppel in der Römischen Architektur. Achitectura 15, pp. 117-39.

Sanpaolesi, Piero. 1971. Strutture a cupola autoportanti. Palladio. Rivista di Storia dell'Architettura e Restauro XXI, pp. 3-64.

Passaro, S., et al. 2012. Multi-resolution morpho-bathymetric survey results at the Pozzuoli-Baia underwater archaeological site (Naples, Italy). In: Journal of Archaeological Science, http://dx.doi.org/10.1016/j.jas.2012.09.035

Verdiani, Giorgio. 2017. From the archaeological reality to the digital reconstruction:an architectural drawing challenge - Dalla realtà archeologica alla ricostruzione digitale: un sfida per il Disegno dell'Architettura. In: Disegnare con, N. 19, pp. 4.14.13 . 